\title{
ENSINO DE LÍNGUA ESTRANGEIRA NO BRASIL: ENTRE A ESCOLHA OBRIGATÓRIA E A OBRIGATORIEDADE VOLUNTÁRIA ${ }^{i}$.
}

\begin{abstract}
Kelly Day é professora do Centro de Língua e Cultura Francesa Danielle Mitterrand, no Amapá, mestre em estudos da Linguagem pela PUC-Rio e doutoranda em estudos aplicados da linguagem pela Universidade Federal Fluminense - UFF. Estuda políticas linguísticas aplicadas ao ensino de línguas estrangeiras no Brasil e linguística aplicada ao ensino do francês língua estrangeira (FLE).

E-mail: kellyday@uol.com.br
\end{abstract}

\section{Resumo}

O artigo propõe uma breve reflexão sobre a política linguística educativa de ensino de línguas estrangeiras no Brasil a partir de conceitos básicos em política linguística, do delineamento de marcos históricos do ensino de línguas no país e da criação da lei 11.161 de 2005 que estabelece um contraponto com a LDB 9394/96. Segundo esta lei não há línguas estrangeiras específicas obrigatórias no ensino brasileiro, mas se o inglês ocupa atualmente o papel de "língua franca" imposta pelo mercado mundial, o espanhol tem um status jurídico de língua de oferta obrigatória em todo o território brasileiro. Isto implica que mesmo nas áreas de fronteira com a Guiana, com o Suriname e com a Guiana Francesa a língua espanhola tem prioridade, fato que repercute negativamente no ensino de outras línguas nessas regiões.

\section{Résumé}

L'article propose une breve reflexion sur la politique linguistique educative d'enseignement de langues étrangères au Brésil à partir de concepts fondamentaux en politique linguistique, du repère d'indicateurs historiques de l'enseignement de langues dans le pays et de la création de la loi 11.161 de 2005 qui se met en oposition à la loi national (LDB) 9394/96, selon laquelle l'enseignement de langues est obligatoire, mais il n'y a pas de langues espécifiques. Néanmoins, si l'anglais, actuellement prend la place de langue franche, imposée para le marché mondial, l'espagnol a le status juridique de langue d'offre obligatoire dans tout le territoire brésilien, y compris les zones frontalières avec la Guyana, la Guyane Française et le Suriname, ce qui réverbère de manière négative sur l'enseignement d'autres langues dans ces régions.

\section{Introdução}

A crescente importância atribuída ao ensino e à aprendizagem de línguas estrangeiras é proporcional ao crescimento que se vivencia, nos dias atuais, nas relações interpessoais entre os povos. Quanto maiores as possibilidades que temos de estabelecer relações comerciais, culturais e contatos pessoais com indivíduos de outras partes do mundo, maior é a importância de dominarmos outros idiomas além da língua materna. Porém, diferente do que muitos podem supor, a definição de quais línguas estrangeiras um Estado ou um povo opta por ensinar ou aprender, no ensino regular, não é fruto do acaso ou de escolhas pouco refletidas. Muito mais do que opiniões pessoais, o que prevalece, mesmo individualmente, em primeira escala é o poder econômico que essa língua representa e em segundo plano a proximidade geográfica e cultural entre os 
falantes, dois elementos que estão na linha de frente na definição da política de ensino de línguas estrangeiras no Brasil.

O ensino de língua estrangeira, segundo Leffa (2005), tem sido abordado nas últimas décadas a partir de duas perspectivas: uma que é preferencialmente metodológica, cujas discussões gravitam em torno do universo da sala de aula e onde se incluem questões que se estendem desde a formação e atuação do professor até temas relativos à construção da identidade do aprendente; e outra, preferencialmente política, que se ocupa de temáticas relativas à escolha da língua estrangeira, ao impacto da hegemonia de uma língua sobre outra, às relações de força estabelecidas entre línguas dentro de um mesmo território, etc. Tais abordagens são dadas, respectivamente, pela linguística aplicada e pela política linguística.

Enveredando pelos caminhos da política linguística, neste texto apresentamos, brevemente, conceitos importantes deste campo de discussão, os eventos que consideramos como marcos da política de ensino de línguas no país ao longo dos últimos séculos e colocamos em discussão o mais recente ato de planificação linguística que se configura na lei 11.161/2005 e suas repercussões em âmbito nacional.

\section{1) Política linguística e ensino de línguas}

Política linguística tem um conceito amplo e abrangente, ela está relacionada a toda decisão tomada por agentes sociais no sentido de orientar o uso de uma ou mais línguas em concorrência em uma dada situação. De modo geral, entende-se por política linguística "o conjunto de escolhas conscientes que são realizadas por um grupo de indivíduos no âmbito das relações entre língua e vida social" (Calvet, 2002, p. 145).

Orquestrada no campo ideológico, ela consiste na identificação, segundo parâmetros relativos, de situações linguísticas não ideais e ideais e dos mecanismos de passagem de uma para outra. A colocação em prática da situação idealizada é função da Planificação Linguística.

$\mathrm{Na}$ esfera da política linguística considera-se que a gestão das línguas pode ocorrer, segundo Calvet (2007), in vivo quando as decisões decorrem das práticas sociais, ou seja, das soluções encontradas pelas pessoas no seu dia a dia para uma dada situação linguística ou in vitro quando procedem do poder público, quando são fruto da intervenção do Estado, pela via das leis e decretos, sobre essas práticas.

Por outro lado, uma política linguística intervém em dois domínios: 1) no status das línguas em presença, que diz respeito ao reconhecimento das línguas como línguas nacionais, oficiais, co-oficiais, etc.; ao uso das línguas em diferentes domínios ou ao reconhecimento de direitos linguísticos; e 2) no corpus das línguas que abrangem as intervenções na norma, as reformas ortográficas, modernização de vocabulário, entre outros. 
Ao adentrarmos os domínios do ensino de línguas, materna, segunda ou estrangeira, abordamos um componente específico da política linguística nomeado de política linguística educativa. Tal componente, dentre as escolhas conscientes realizadas no âmbito de uma política de língua, se limita àquelas que tratam exclusivamente do ensino e da aprendizagem das línguas (PetitJean, 2006) e se apresenta referendado através de leis, decretos e orientações educacionais.

A noção de política linguística educativa se desenvolveu nos anos 1990 e se expandiu ao longo da primeira década do século XXI. Ela abrange tanto as políticas de ensino e de uso das línguas nos sistemas educativos, principalmente públicos e oficiais, quanto o conjunto de problemáticas de uma educação cívica para o multilinguismo e para a alteridade linguística (Beacco \& Byran, 2003).

Dentre os exemplos mais recentes de política linguística educativa no Brasil podemos citar, conforme Savedra (2009), tanto exemplos de amplitude nacional quanto local:

- A lei 11.161 dispõe sobre a oferta obrigatória da língua espanhola nas escolas secundárias brasileiras e os Parâmetros Curriculares Nacionais (PCN) que orientam, entre outras coisas, o ensino de línguas estrangeiras;

- A Lei Municipal 987 de 27 de junho de 2007, referente à co-oficialização da língua Pomerana no município de Pancas e a inclusão da disciplina no currículo escolar das escolas da rede municipal de ensino localizadas nas regiões em que predominam a população descendente de imigrantes no município;

- A Lei Municipal 1136 de 26 de junho de 2009, que trata da cooficialização da língua Pomerana no município de Santa Maria de Jetibá, (ES) e a inclusão da disciplina de estudo da língua no currículo escolar, nas escolas da rede municipal;

- O Projeto legislativo 132 de 9 de fevereiro de 2010, que dispõe sobre a co-oficialização da língua Hunsrückisch no município de Antônio Carlos, (SC) e a inclusão da disciplina de estudo da língua no currículo escolar nas escolas da rede municipal de ensino.

Tradicionalmente as instâncias do Estado, seus dirigentes e responsáveis são os principais agentes no âmbito da política linguística educativa, mas outros atores influentes vêm continuamente ampliando sua participação e seu grau de importância nas decisões. Estes novos agentes são as comunidades locais, as instituições culturais, associações, universidades, empresas e as regiões, sobretudo as fronteiriças.

Ainda que os termos política e planificação linguística e sua vertente educativa sejam relativamente recentes na literatura, o mesmo não se pode dizer das ações que 
delimitam as políticas linguísticas implementadas em nosso país e no mundo, sejam elas relacionadas ao ensino da língua oficial sejam relativas ao ensino ou não de línguas estrangeiras.

Vistas historicamente como o espaço do outro e frequentemente utilizadas como instrumento de dominação, as línguas, "oficiais ou estrangeiras", representam também uma área de embate nos sistemas de ensino das sociedades contemporâneas, cujas políticas linguísticas educativas estão sujeitas às forças ideológicas dominantes e às influências das relações de mercado em voga. Assim foi no final do século XIX, quando por influência cultural francesa o francês era preponderante nas escolas brasileiras; assim é hoje, vez que por influência do poder político e econômico americano, bem como das políticas dos grandes mercados temos, por extensão, a presença hegemônica da língua inglesa nos currículos escolares mundo afora.

\section{2) Política linguística educativa: o ensino de línguas estrangeiras no Brasil.}

Ao longo da história do ensino de línguas estrangeiras (LE) no Brasil, é possível identificar uma série de ações de política e planificação linguística que demarcam um processo de avanços e retrocessos na questão.

Embora a língua portuguesa seja considerada em termos práticos a primeira língua estrangeira ensinada no Brasil, ela não o foi em função de determinação legal da coroa portuguesa, mas das necessidades e interesses de comunicação com os indígenas, fato que servia não apenas aos objetivos dos jesuítas, mas também aos da metrópole. Enquanto essa situação foi interessante para os colonizadores, essa condição do português língua estrangeira perdurou, mas à medida que o avanço da língua geral ameaça o domínio português surgem os primeiros atos oficiais de intervenção linguística no Brasil.

O primeiro marco de política linguística educativa que repercute diretamente na relação do povo brasileiro com a língua portuguesa e com as demais línguas (Rodrigues, 2004) é o Diretório de Marquês de Pombal de 1758. A proibição do uso e ensino das línguas indígenas e da língua geral é uma ação de planificação linguística que vai afetar radicalmente a história das línguas no Brasil e o status da língua portuguesa no território. O português deixa de ser língua estrangeira e passa a ocupar o papel de língua nacional e oficial, e as línguas estrangeiras, em consonância com os ideais da época, passam a ser as chamadas línguas de cultura, as línguas clássicas: o latim e o grego.

Outro evento histórico para o ensino de línguas no Brasil que repercute e reflete a política linguística no Brasil Império em âmbito nacional é a criação do Colégio Pedro II em 1837. Um dos primeiros estabelecimentos oficiais de estudos secundários no Brasil, ele introduz também pela primeira vez, no currículo das escolas brasileiras, as línguas estrangeiras modernas em pé de igualdade com as línguas clássicas. Baseado no modelo francês de ensino, o programa incluía aulas de francês, inglês e alemão no colegial. Cabe lembrar, porém, que baseado no modelo francês de educação, o ensino de 
línguas estrangeiras estava diretamente relacionado ao culto do espírito e à formação clássico-humanista almejada pela elite, visando ao ingresso nas universidades. A base fundamental do colegial clássico eram os estudos literários, cujos instrumentos principais de ensino eram textos em línguas estrangeiras clássicas ou modernas.

Além de tornar-se o colégio modelo de ensino secundário para todo o país, o Colégio Pedro II também era o primeiro e único, à época, a realizar os exames que possibilitavam o ingresso nos cursos superiores.

Considerando que uma política linguística não raro está atrelada a um contexto geopolítico e econômico mais amplo, é válido dizer que a criação do Colégio Pedro II é um ato que vem dar respostas às demandas e anseios surgidos com a chegada da família real ao Brasil. A vinda da família real traz consequências para o país tanto no plano econômico quanto cultural e educacional. Com a corte vieram as companhias de teatro, fundaram-se as academias militares e as escolas de direito e medicina, abriu-se a Imprensa Régia e dá-se também, por conseguinte, a abertura dos portos, fatos que vão impor a necessidade de oferecer-se educação nos moldes europeus aos filhos da nobreza, e o uso de outras línguas, que não as clássicas, principalmente nas ações comerciais estabelecidas com a Inglaterra, a grande potência econômica e militar da época.

Durante o Império, os alunos estudavam no mínimo quatro línguas no ensino secundário (Leffa 1999), em contrapartida, ainda que a criação do Colégio Pedro II tenha representado um avanço inegável para o ensino de modo geral e, particularmente, para o de línguas estrangeiras modernas no Brasil, do final do Império às primeiras décadas da República, o ensino de modo geral, e por extensão o de LE, foi objeto de mais de uma dezena de reformas que acabaram por configurar um declínio contínuo nesse ensino, tanto no que concerne ao número de línguas ensinadas quanto ao número de horas semanais a elas dedicadas, conforme podemos constatar no quadro abaixo.

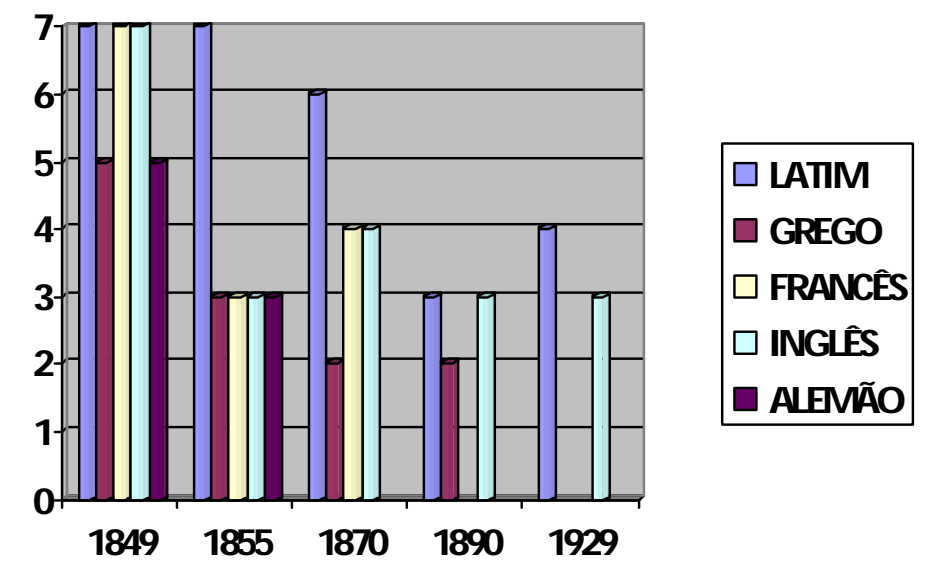

Figura 1: Evolução do ensino de línguas estrangeiras no Brasil entre 1849 e 1929 
No século XIX, no final da década de 40, em 7 anos de estudos, enquanto a Gramática geral e nacional só aparece nos primeiros anos, o latim, o francês e o inglês são ensinados ao longo de todo o colegial, além do alemão e do grego ensinados durante 5 anos (Moacyr, 1936). Em 1855, por exemplo, das 24 horas semanais do currículo, cerca de 15 horas, em média, eram destinadas ao ensino de línguas estrangeiras, porém, à exceção do latim, elas eram ministradas apenas durante 3 anos de curso. Menos de um século depois, em 1929, das 5 línguas estrangeiras ensinadas no Brasil Império apenas duas permanecem no currículo ao final do $1^{\mathrm{a}}$ República.

A República, em muitos sentidos, representa um divisor de águas na história da educação no Brasil, mas também corresponde ao princípio de uma queda vertiginosa do ensino de línguas estrangeiras. À medida que a educação passa a ser vista como um instrumento de reprodução das relações de produção, voltada para a instrumentalização para o trabalho, o que na época não incluía necessariamente falar outras línguas como ocorre atualmente, as línguas estrangeiras deixam de ter a importância do passado e o tempo dedicado a elas diminui na mesma proporção da entrada de novas disciplinas na grade curricular.

As sucessivas reformas que ocorreram ao longo da primeira e segunda República, dentre elas a reforma Francisco de Campos que instituiu o método direto como método oficial, foram paulatinamente promovendo alternância entre as línguas priorizadas, apresentando-as ora como obrigatórias ora como facultativas e reduzindo consideravelmente o número de aulas semanais. É só com a Reforma de Capanema em 1942, outro marco do ensino de LE no Brasil, que este quadro se modifica.

A Reforma de Gustavo de Capanema de 1942, formulada com base nas ideias positivistas, manteve e reforçou alguns projetos iniciados com a reforma anterior e deu ênfase à formação geral do aluno adotando um programa que volta a valorizar as disciplinas clássicas e conteúdos que enfocam questões nacionalistas. Foi essa a reforma que maior importância atribuiu ao ensino de línguas estrangeiras no Brasil República. Do ginásio ao colegial (científico ou clássico), além do latim estudava-se francês, inglês e espanhol.

A despeito de todo o centralismo e autoritarismo que marcou o Estado Novo, especialmente neste caso pela ação repressiva contra as escolas mantidas pelas colônias alemãs e italianas no sul do país, foi através da Reforma de Capanema que se destinou 35 horas semanais ao ensino de idiomas (clássicos e modernos) e também se estimulou nas escolas a aplicação do método direto. De orientação eminentemente prática, ele pregava o ensino da LE na própria LE, um indicativo de preocupação com os aspectos metodológicos do ensino.

Com a centralização do ensino, todas as decisões deveriam passar, necessariamente, pelo Ministério da Educação, desde as línguas que deveriam ser ensinadas até a metodologia e o programa a ser desenvolvido em cada série, conduzindo 
assim a uma homegeneização das políticas educativas em todo o país. Ainda assim, de acordo com Leffa (1998:11), observadas de uma perspectiva histórica, "as décadas de 40 e 50, sob a Reforma Capanema, foram os anos dourados das línguas estrangeiras no Brasil".

No entanto, todo avanço representado pela supracitada reforma desaparece com a promulgação da LDB de 1961 e o ensino de línguas tem seu golpe de misericórdia com a 5692/71. Na contramão das expectativas, a descentralização do ensino promovida pela LDB de 1961 repercute diretamente no ensino de LE, que deixa de ser obrigatório e fica sob a responsabilidade dos Conselhos Estaduais de Educação.

Paralelamente, no contexto geopolítico, a emergência dos Estados Unidos póssegunda guerra como potência militar, política e econômica é o que vai determinar, por um lado, o crescente espaço da língua inglesa em território nacional e provocar o boom das escolas privadas de inglês; e, por outro, reduzir a influência cultural e econômica de outros países como França e Alemanha, bem como a busca pela aprendizagem de suas respectivas línguas.

Em 1971, além de sujeitar o ensino de LE "às condições de cada estabelecimento", fato que levou a uma redução drástica na oferta de línguas estrangeiras, a LDB 5692 reduz o ensino de 12 para 11 anos e introduz a habilitação profissional. Como resultados imediatos, muitas escolas aboliram o ensino de línguas estrangeiras ou reduziram a carga horária para (1) uma hora semanal.

Na direção contrária ao que ocorria no mundo, relativamente à expansão das pesquisas em linguística aplicada ao ensino de línguas, e ignorando os apelos de muitos setores da sociedade que reconheciam a importância do ensino de LE, as políticas linguísticas educativas advindas com a 5692/71 não asseguraram a permanência, com qualidade, desse ensino nas escolas brasileiras e, ainda, intensificaram o senso comum de que não se aprende línguas estrangeiras nas escolas regulares.

Conforme podemos constatar no quadro abaixo, em cerca de 30 anos passou-se de um efetivo ensino de línguas de caráter obrigatório, o que refletia com maior fidelidade uma política plurilíngue e multicultural, à retirada total desse ensino das escolas brasileiras entre as décadas de 1960 e 1970. Posteriormente, em meados da década de 1990, o ensino de línguas foi retomado, já em uma perspectiva de hegemonia linguística da língua inglesa. 


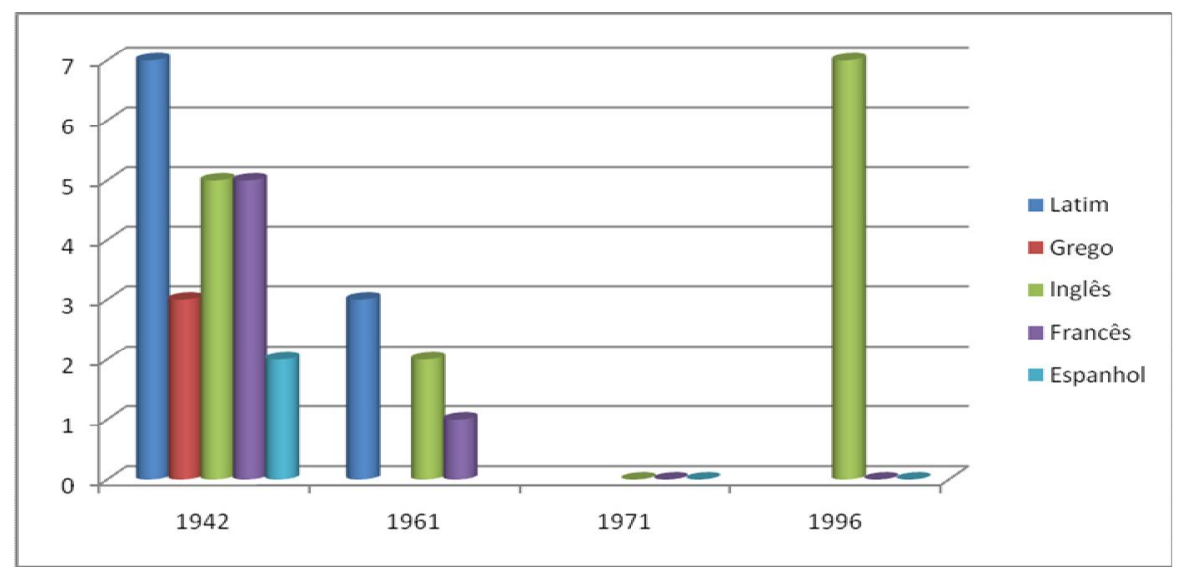

Figura 2: Oferta de línguas estrangeiras a partir da Reforma Capanema

É com a LDB 9394/96 que as línguas estrangeiras voltam, na prática, a figurar no currículo com caráter obrigatório a partir da $5^{\mathrm{a}}$ série. Embora com limitações, dadas às condições da escola pública brasileira, com um número de horas reduzido e apenas com uma língua obrigatória, ela representa uma reavaliação positiva e um realinhamento do ensino de LE no Brasil.

Finalmente, a assinatura do tratado do MERCOSUL configura-se como o mais recente marco político-econômico que direciona a história do ensino de línguas no país. Este tratado, desde seu início, estabelece o ensino do espanhol e do português nos países membros como um dos objetivos estratégicos do bloco, de modo que se favoreçam as relações, sobretudo as comerciais, entre os povos.

Tal qual na Europa, assistimos com a criação do MERCOSUL a um estreitamento dos vínculos econômicos e políticos na América do Sul, fato que tem repercutido diretamente nas questões linguísticas, permitindo definir novas dinâmicas no ordenamento linguístico regional. Os impactos destas transformações abrem caminho para uma tomada de consciência da diversidade linguística e para o reconhecimento da coexistência das línguas, não apenas no Brasil, mas em toda a região.

O Brasil, ao comprometer-se a promover a integração entre os povos do bloco, compromete-se, também, com a divulgação e a expansão em território nacional da língua espanhola, decisão que impulsiona a abertura em diversas universidades de licenciaturas em espanhol, de cursos de espanhol em tradicionais escolas de inglês e repercute, diretamente, na mais recente ação de política e planificação linguística no Brasil, a lei 11.161/2005.

\section{3) O ordenamento linguístico brasileiro atual: Entre a escolha obrigatória e a obrigatoriedade voluntária.}


Atualmente, o ensino de línguas no Brasil é regido por duas leis: a LDB 9394/96 que se caracteriza pela ênfase dada à escolha da(s) língua(s) estrangeira(s), ou seja, que valoriza e possibilita uma política in vivo; e a lei 11.161/2005 que determina a obrigatoriedade de oferta da língua espanhola, na qual prevalece o in vitro, ambas atuando no âmbito do status das LE.

A LDB 9394/96, compreendida nesse texto como a escolha obrigatória, determina que a partir da $5^{\mathrm{a}}$ série pelo menos uma língua estrangeira moderna deverá ser ensinada, esta escolha está a cargo da comunidade escolar, em outras palavras, o que estabelece a lei é que, ainda que obrigatória, a língua estrangeira (francês, inglês, alemão, etc.) deverá ser eleita pela comunidade, não cabendo, portanto, tal escolha nem ao professor, nem ao dirigente escolar, nem propriamente ao Estado.

No ensino médio, de igual maneira, deve-se ofertar duas línguas estrangeiras modernas, uma obrigatória e uma outra de caráter opcional.

Em complemento à LDB foram lançados os Parâmetros Curriculares Nacionais (PCN, 1998), que baseados nos princípios da transversalidade, orientam o ensino de línguas estrangeiras. De acordo com os PCN, a escolha da língua estrangeira em uma dada comunidade deve basear-se em três fatores:

- Os fatores históricos que levam em conta o papel hegemônico que exerce uma determinada língua no contexto das relações internacionais, elemento que corrobora, na atualidade, a importância e a escolha da língua inglesa na grande maioria das escolas brasileiras;

- Os fatores relativos às comunidades locais, elementos provenientes da convivência entre comunidades contíguas com línguas diferentes, tal é o caso das comunidades linguísticas de fronteira (neste âmbito inclui-se o francês, o espanhol, o guarani e mesmo o inglês) e as comunidades de imigrantes (cujas colônias justificam a adoção do italiano, do alemão, do japonês, além de outros dialetos regionais que se mantêm);

- E os fatores relativos à tradição, os quais levam em conta o papel de uma dada língua nas relações culturais estabelecidas entre nações e no acesso ao conhecimento. Fator decisivo quando analisamos a importância cultural do francês, do alemão e do espanhol, entre outras.

Tais elementos são os eixos que possibilitam a ampliação das possibilidades de escolha e colocam o ensino de línguas no âmbito da pluralidade linguística brasileira, abrindo espaço para o ensino regular de línguas consideradas efetivamente como estrangeiras ou como segunda língua de diversas comunidades, especialmente no sul do país.

Na perspectiva inversa a da LDB, interpretamos a lei 11.161 de 2005 como uma obrigatoriedade voluntária uma vez que mesmo sendo de oferta obrigatória para a 
escola, a língua espanhola deveria ser uma opção adotada pelo aluno individualmente ou pela comunidade escolar e jamais imposta, como vem ocorrendo em algumas partes do país.

Isto posto é válido dizer, que se assim não o for (escolha pessoal ou comunitária), corre-se o risco de sair de uma política hegemônica de ensino de línguas, representada pela prevalência da língua inglesa, para adotar-se uma nova, a da língua espanhola, ignorando não apenas a formação do cidadão plural, a abertura para o plurilinguísmo e multiculturalismo de que trata a constituição federal, mas também, e sobretudo, as diferenças culturais e geopolíticas das comunidades brasileiras, entre elas as de imigrantes e as de fronteira.

Cabe lembrar, portanto, que para as diferentes realidades brasileiras, diferentes escolhas são possíveis. Não cabe ao Estado, definir quais critérios ou fatores são mais ou menos relevantes para uma dada comunidade. $\mathrm{O}$ critério que justifica a escolha do espanhol na fronteira com a Argentina, Paraguai ou Bolívia pode não ser o mesmo que justifica a escolha do espanhol em Brasília ou em São Paulo, seja pelo aspecto econômico, cultural ou espacial, e isso é válido para qualquer outra língua e para qualquer outra região.

Se por um lado a globalização promove uma integração planetária entre sociedades, o que implica na divulgação de certos esquemas culturais, por outro ela também se caracteriza pelo acirramento dos processos de individualização e autonomia identitária. Em outras palavras, ao mesmo tempo em que o indivíduo quer estar integrado ao mundo globalizado, ele quer ter sua identidade regional ou local reconhecida como tal, inclusive no reconhecimento das relações estabelecidas através das línguas que o cercam.

Ao analisarmos o atual quadro jurídico do ensino de LE no Brasil, não podemos ignorar que no contexto global o inglês impõe-se pelo que representa política e economicamente no mercado mundial, o espanhol, num âmbito supranacional, tem oficialmente status de língua estrangeira obrigatória no Brasil, dois elementos que por si só eliminam as reais possibilidades de escolha de que trata a 9394/96, considerando-se que a escolha, em última análise, é referente às outras línguas que não a espanhola, segundo o que se estabelece com a 11.161/2005. Nestes termos, nenhuma escola efetivamente tem a opção de ofertar apenas uma língua, (diante da impossibilidade de se ofertar duas ou mais) se esta não for o espanhol, independente de quais sejam os fatores motivacionais.

E quando estendemos esta reflexão para as comunidades de imigrantes ou de fronteira podemos constatar que entre a escolha obrigatória e a obrigatoriedade "pseudo" voluntária só se pode escolher, quando há condições para tanto, entre inglês e espanhol ou alemão e espanhol ou francês e espanhol, ou italiano e espanhol, etc. tornando as possibilidades de ofertar-se alemão e inglês ou inglês e francês inviáveis, dadas as reais (e não as ideais) condições da escola pública. A lei, por si só, não abole 
os problemas pré-existentes nos espaços escolares, mas pode trazer outros não previamente previstos.

Na prática, o espanhol é a única língua estrangeira obrigatória no Brasil e todas as demais são opcionais, o que também significa dizer que a obrigatoriedade imposta pela 11.161/2005 fere, em certa medida, o direito de escolha assegurado pela LDB 9394/96. Diante da obrigatoriedade de ofertar-se uma língua e da impossibilidade de ofertar-se também uma segunda ou terceira, caso de diversos municípios, nos mais recônditos lugares do país, o dirigente escolar não encontra muitas opções, senão a de "voluntariamente" seguir a lei que impõe e não aquela que abre possibilidades, e assim, no Amapá, por exemplo, fronteira com a Guiana Francesa, o caminho mais comum, para não dizer o mais fácil, tem sido o de ofertar espanhol, mesmo que a fronteira, a realidade sócio-econômica, as relações históricas e a vontade da comunidade apontem para a necessidade do ensino do francês.

\section{4) Considerações finais}

Neste breve panorama apresentado sobre a política linguística educativa de ensino de línguas estrangeiras no Brasil ao longo dos últimos séculos, é claramente observável que tais políticas estão fortemente relacionadas com contextos históricos e econômicos e interesses comerciais nem sempre favoráveis ou benéficos ao ensino de línguas.

O forte ensino de línguas estrangeiras observado no Brasil Império era muito mais uma tentativa de aproximação e manutenção de vínculos culturais da corte com a Europa e seus modos de vida do que uma política linguística de abertura para a pluralidade linguística brasileira que já se abria para as línguas de imigração.

Entre outros elementos, é a imigração que ocorreu ao longo do século XIX e XX que pode justificar no ensino, pelos vínculos sócio-históricos que estabelece com seus descendentes no Brasil de hoje, diferentes possibilidades de escolha entre as línguas de imigração brasileiras, entre elas o Hunsrückisch, o Talian, o Pomerano, etc. de acordo com a região onde elas são representativas.

Consideramos que é a clareza da existência dos diferentes mosaicos brasileiros que poderá abrir caminhos tanto para a defesa dos ambientes linguísticos quanto para a democratização do ensino de línguas segundas e/ou estrangeiras. Em todas as instâncias de discussão do ensino fica cada dia mais evidente que as políticas linguísticas educativas relativas ao ensino de línguas estrangeiras devem estar alinhadas ao panorama geopolítico em que ocorrem. É nesse sentido que acreditamos que uma política linguística educativa formulada em uma perspectiva geral de respeito às diferenças, de valorização da diversidade e que abra espaço, verdadeiramente, para as escolhas em um país de dimensões tão amplas e tão multifacetado linguística e culturalmente como o Brasil, seria muito mais justa e adequada. 
A lei que torna obrigatória a oferta do espanhol, em que pese todo o contexto histórico, social e econômico no qual ela se insere e a importância de que se reverte no âmbito do MERCOSUL, remete à política monolinguísta que impera em torno da língua oficial brasileira. Embora as fronteiras brasileiras sejam majoritariamente com países de hispanofalantes, elas não são as únicas e, assim, ofertar espanhol, em detrimento de línguas com as quais uma dada comunidade linguística administra relações culturais históricas, parece ser um retrocesso.

Observar os critérios apontados nos PCN pode ser um caminho para que o poder público elabore políticas mais condizentes com o ambiente linguístico de uma comunidade, partindo, sobretudo, do efetivo papel que uma determinada língua ocupa no contexto de uso.

É fato comum que nem sempre as políticas linguísticas institucionalizadas pelo Estado refletem as escolhas linguísticas de uma comunidade, mas também é função da política linguística colocar em discussão estas questões. O espaço territorial brasileiro compreende diferentes contornos linguísticos que precisam ser respeitados em suas diversidades. Em uma política linguística equânime é necessário considerar por um lado que as fronteiras nacionais não estão restritas a países de língua espanhola como é o caso da fronteira com a Guiana Francesa e o Suriname, e por outro, que as comunidades descendentes de imigrantes, por exemplo, podem querer estudar outras línguas que não o inglês e o espanhol.

\section{Referências Bibliográficas}

BEACCO, J-C \& BYRAN, M. Guide pour l'élaboration des politiques linguistiques en Europe, Conseil de l'Europe, Strasbourg, 2003.

BRASIL. Secretaria de Educação Fundamental. Parâmetros curriculares nacionais: terceiro e quarto ciclos do ensino fundamental: língua estrangeira. Brasília: MEC/SEF, 1998.

CALVET, L-J. Sociolinguística: uma introdução crítica. Tradução Marcos Marcolino. São Paulo: Parábola, 2002.

As políticas linguísticas. Tradução Isabel de Oliveira Duarte, Jonas Tenfen, Marcos Bagno. São Paulo: Parábola Editorial: IPOL, 2007.

LEFFA, Vilson J. "O professor de línguas estrangeiras: do corpo mole ao corpo dócil". In: FREIRE,M. \& all.(orgs). Linguística Aplicada e Contemporaneidade. Campinas, SP: Pontes, 2005, p. 203-218. 
LEFFA, Vilson J. O ensino das línguas estrangeiras no contexto nacional. Revista Contexturas/Ensino Crítico da Língua IngLEa. Vol.4. São Paulo: APLIESP, 1998, p. 13-24.

MOACYR, Primitivo. A instrução e o Império (subsídios para a História da Educação no Brasil): 1823-1853. São Paulo: Companhia Editora Nacional, 1936.

PETITJEAN, Cecile. Plurilinguisme et politique linguistique éducative en Europe: de la théorie à la pratique. Revue Printemps/Spring, vol I, nº 2, 2006, p. 98-125.

RAJAGOPALAN, K. "O ensino de línguas estrangeiras como uma questão política". In: MOTA, K. \& SCHEYERL, D. (Orgs.), Espaços Linguísticos: resistências e expansões. Salvador: EDUFBA, 2006.

RAJAGOPALAN, K. Política linguística e a política da linguística. In: D. SIMÕES; C.C. HENRIQUES (Orgs). Língua Portuguesa, Educação \& Mudança. Rio de Janeiro, Ed. Europa, 2008, p. 11-22.

RODRIGUES, F. S. C. A língua espanhola no ensino superior em São Paulo: histórias e Perspectivas. In: Hispanismo 2004. Florianópolis: Editora da UFSC, PP. 177-189

SAVEDRA, M.M. Leis, Projetos e ações de política e planejamento linguístico após 1996. 2009. Disponível em www.ipol.org.br.

\footnotetext{
${ }^{\text {i }}$ Este Artigo faz parte da pesquisa que está sendo desenvolvida no programa de pós-graduação, em nível de doutorado, na Universidade Federal Fluminense sob o tema "Línguas em contato e políticas linguísticas em conflito na fronteira Brasil/Guiana Francesa" sob a orientação da professora pós-doutora Mônica Maria Guimarães Savedra.
} 